\title{
Requiring Certain Physical Enhancements For Internet Courses: A Survey
}

\author{
Gary Saunders, (Email: saunderg@marshall.edu), Marshall University
}

\begin{abstract}
Use of the Internet continues to increase and new technology provides more and better communication options. A questionnaire was distributed to chairpersons of accounting departments to obtain their views on requiring some of these newer physical enhancements on a student's computers when they register for an E course. Respondents strongly favored requiring students to provide a digital photo ID and audio capabilities when registering for an E course but rejected the idea of requiring them to provide a web cam that might be used for verifying their identity. They also tended to believe, even though they did not endorse requiring one, students should use a web cam when completing examinations on-line and that faculty should compare the photo ID with the web cam image. However, they do not believe that students should be required to use a web cam when completing homework assignments or that faculty should compare the photo ID with the web cam image. Overall accounting chairs endorse requiring the student who enrolls in an E course to obtain some existing technology and they expect the student to be prepared to spend more than $\$ 100$ to obtain the technology
\end{abstract}

\section{INTRODUCTION}

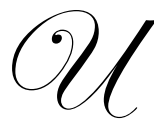

se of the Internet continues to increase and new technology provides more and better communication options. The increasing use of the Internet has been accompanied by a proliferation of Internet (E) courses and degree programs. The 1993 Peterson $=\mathrm{s}$ College Guide listed $93>$ cyberschools $=$ and the 1997 Distance Learning Guide listed 762. That represents a phenomenal growth of more than 700 percent. Vasarhelyi and Graham [1997, p. 32] state that Ain the last two years, the emergence of the Internet has opened the doors for a permanent revolution in the classroom and educational processes. . About 55\% of America $=\mathrm{s} 2,215$ colleges and universities have courses available off site. @ By 1998 approximately 1,680 institutions were offering about 54,000 E courses with 1.6 million students enrolled. Svetcov reported that in:

ADecember 1999, the National Center for Educational Statistics (NCES) of the U.S. Department of Education (USDE) released a national survey on what it calls Adistance learning $@$ in higher education. In 1997-98 almost 44\% of all higher education institutions offered distance courses. Larger institutions moving faster; $87 \%$ of those with more than 10,000 students offered distance classes while only 19\% of institutions with fewer than 3,000 students did so. Total enrollment in postsecondary, credit-granting distance learning courses in 1997-98 was 1,363,670; the number has grown considerable since, although as yet there are no firm figures. @ [Forbes, 2000]

The American Federation of Teachers indicated that Adistance education is one of the fastest-growing developments in higher education. Seventy percent of the nation=s 4,000 two- and four-year colleges offered online courses in 2000, up from 48\% in 1998@ [Black Issues in Higher Education, 2001]. One website [http://www.collegeathome.com/] contains the statement that it can put the reader in contact with Aover 500 U.S. Universities and Colleges, ALL fully ACCREDITED, offering degrees in over 900 different fields (over 10,000 different programs offered) from Bachelor $=$ s to Doctorate $=$ s . ." The website goes on to list some of the most highly respected universities in the U.S. Add to that the large number of colleges and universities that are not accredited and the more than 1,600 corporate universities [elearning, www.elearningmag.com, October, 2001] offering Internet courses and the growth in Internet course offerings is amazing. 
In many ways $\mathrm{E}$ courses represent a major departure from the traditional learning model. In a survey of accounting chairpersons Saunders (2002) found that by a more than 9 to 1 margin, accounting chairpersons believe that the level of control an instructor possesses with Internet courses is substantially less that with traditional courses. Uncertainty over who is actually completing the assignments in correspondence courses exists with $68.7 \%$ saying they are less certain than with traditional courses. Do E courses make it easier for a person to obtain credit for a course, or degree, while having another person actually complete the exams and assignments? Is it more likely that individuals will falsely obtain degrees from previously reputable colleges and universities by proxy? Eisenberg (1999) suggests that eliminating cheating on exams administered in Internet courses is not possible without a face-to-face proctor. He does concede, however, that some electronic tool are available that, while not the best cost effective approach, can help mitigate the problem of insuring that the person receiving credit for an Internet course is actually completing the requirements for the course.

Smith [Smith, IAEC 2000] discussed some of the advantages and disadvantages of Internet courses and pointed out, among others, the following disadvantages.

1. Internet courses are not for all students,

2. Students must have the requisite computer skills to complete an Internet course,

3. Face-to-face interaction is missing,

4. Courses must be prepared in detail and approved before being offered and are rather unyielding to change,

5. Communications must be very precise and many students and faculties are not proficient at communicating explicitly.

Some of the new communication devices, such as a digital photo ID, a web cam, or audio capabilities could serve to lessen some of these concerns.

\section{STUDY RESULTS}

Accounting department chairpersons typically play a major role in the development of Internet accounting courses and in setting the requirements for them. In order to obtain the opinions held by accounting chairpersons regarding the desirability of requiring some of the available electronic tools for improving communication in E courses, a questionnaire was developed and $\mathrm{E}$ mailed to 471 chairpersons of accounting departments at universities and colleges in the U.S. Of that 471, 69 were undeliverable because of addressing problems leaving 402 delivered questionnaires. A total of 56 responses $(14 \%)$ were received. Statements in the questionnaire also related to the demographics of the respondent's school and program.

Questionnaires were sent via E mail and three different response modes were suggested. If respondents were concerned about anonymity, it was suggested that they either 1) print the questionnaire, complete it, and mail it to the author or, 2) click on an Internet address and complete a web page version. Both of these response methods would help insure anonymity. The third method of responding was to choose Areply@ in their E mail program, complete the questionnaire, and click on Asend.@ Responses began arriving within hours of the initial mailing.

\section{Offering and Teaching E Courses}

Two statements referred to whether the respondent $=\mathrm{s}$ college or university offered $\mathrm{E}$ courses and whether the respondent had actually taught an E course. As shown in figure 1, 74.5\% of the schools offer E courses and $29.1 \%$ of the respondents have taught a course on the Internet. Results of a study completed about two years ago indicated that about the same portion of schools (75\%) offered E courses but the percentage of respondents that had actually taught an E course was only $12.2 \%$. Those data may suggest that the number of $E$ courses offered in accounting is increasing. 
Figure 1

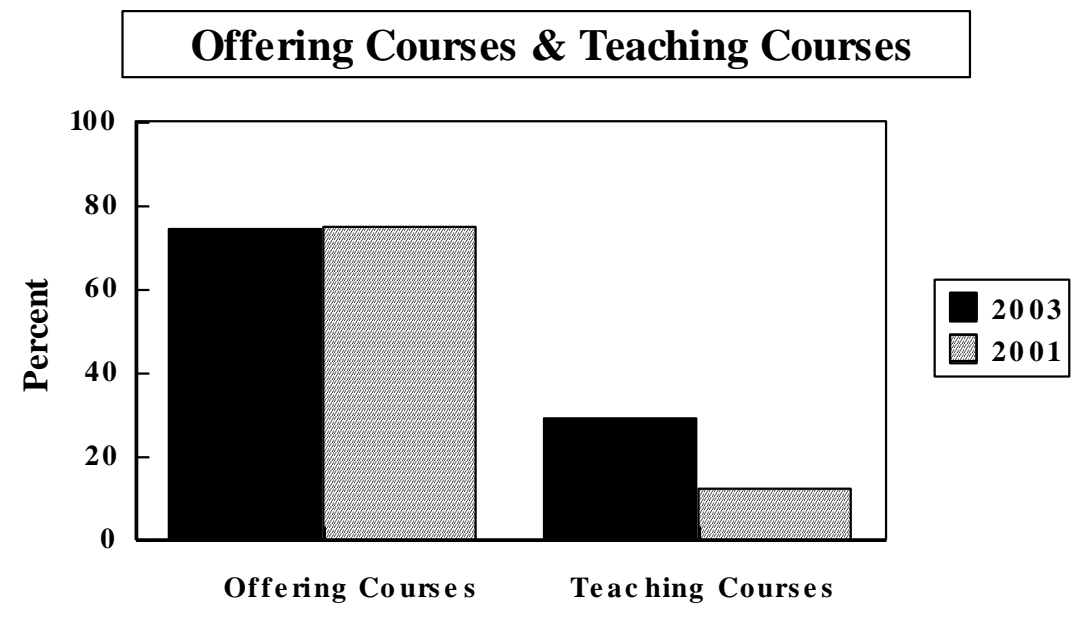

\section{Physical Enhancements}

A number of statements dealt with the possibility of requiring certain controls, such as the use of digital photos for identification or using web cams and audio capabilities for students completing exams, homework assignments or communicating in chat rooms as part of the requirements for an E course. Figure 2 indicates that only about $6 \%$ of the respondents objected to requiring students to provide a digital photo when registering for an E course while more than $66 \%$ agreed that it should be used. This photo could then be used for confirming the identity of the student who completed exams or homework assignments on-line or engaged in chat room sessions. This control measure is relatively cost free and that may be a factor in the recommendation by two-thirds of the accounting chairpersons that it be used.

Figure 2

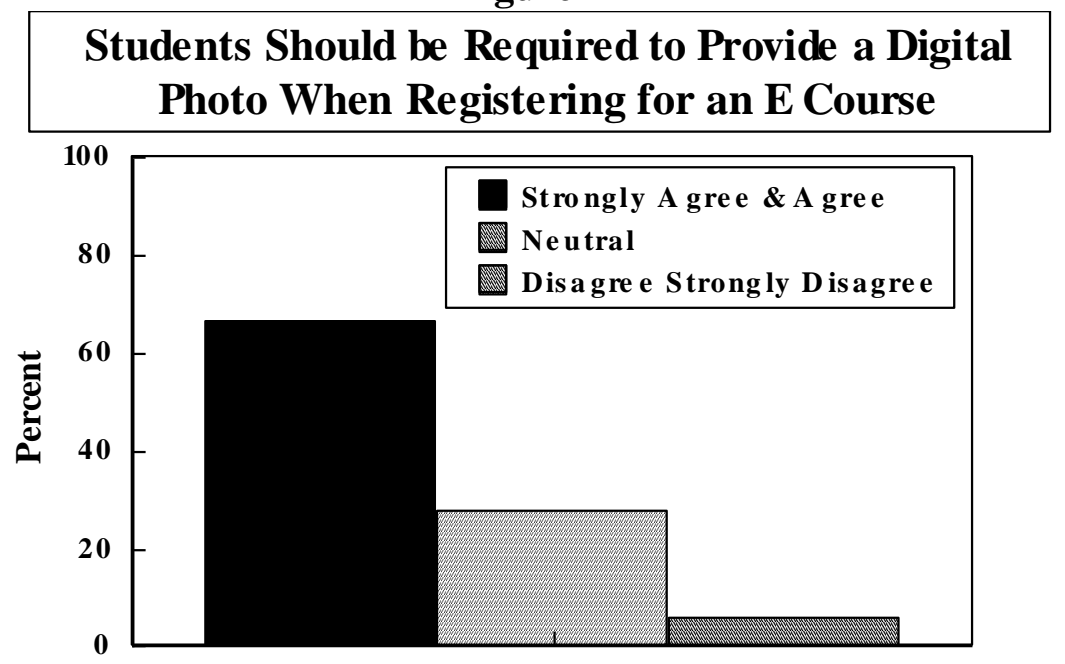


As shown in figure 3 , a larger percentage, slightly over $35 \%$, disagreed with requiring a student to provide a web cam when registering for an E course. Still, with more than $25 \%$ agreeing and nearly $40 \%$ neutral, almost two-thirds did not object to the requirement. The perceived cost of a web cam may have influenced those who objected.

Figure 3

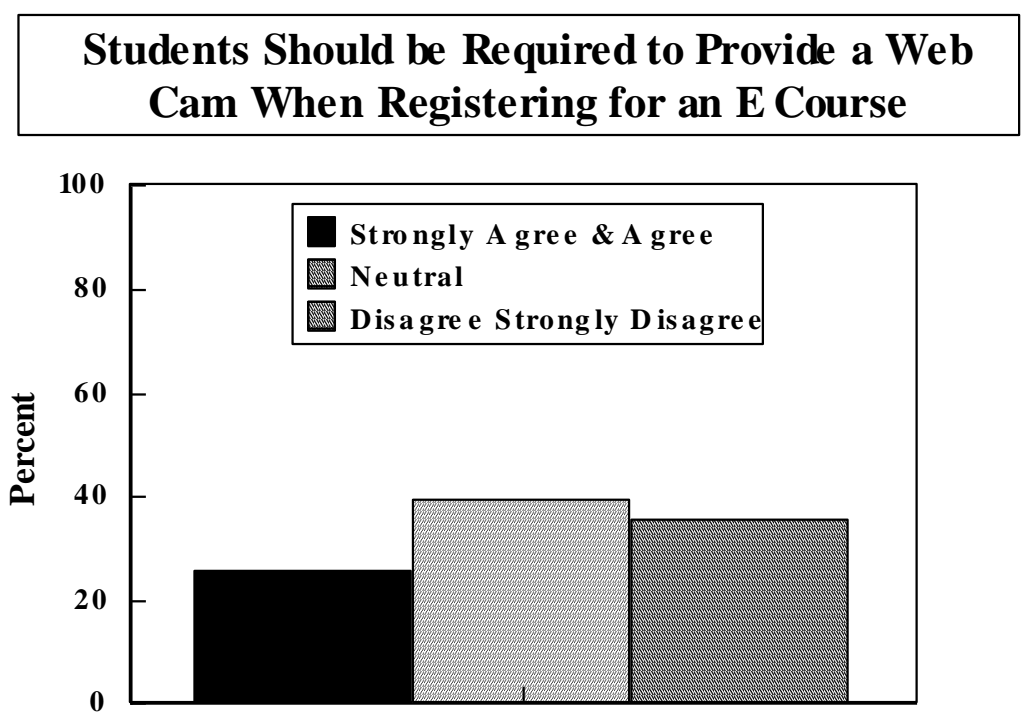

Another statement considered requiring the student to obtain audio capabilities when registering for an E course. Audio capabilities would not only act to improve control but would also make student-instructor conferences much more productive. As shown in the figure 4,53\% agreed or strongly agreed that students should be required to obtain audio capabilities when registering for an E course. With more than $37.2 \%$ of the respondents being neutral and only $9.8 \%$ disagreeing with the requirement, more than $90 \%$ did not object.

\section{Figure 4}




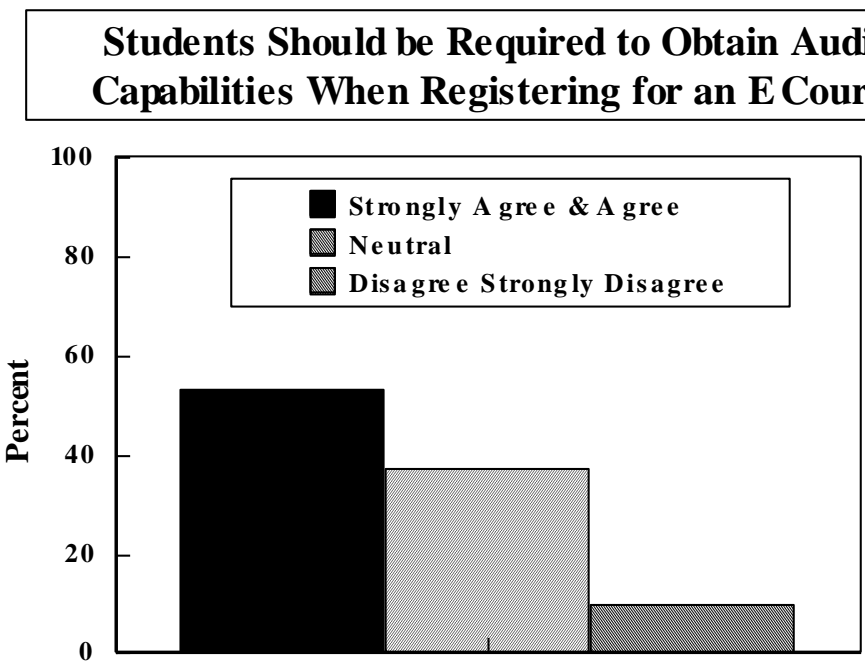

A related statement said Ain order to obtain the $>$ desired technology $=$ for completing an $>$ E course, $=$ students should be prepared, if necessary, to spend the following amount of money to upgrade their computer.@ As the response percentages in the figure 5 indicate, almost $40 \%$ indicated that students should be prepared to spend more than $\$ 150$ to upgrade their computers for an E course and another $20 \%$ said they should be prepared to spend from $\$ 100.01$ to $\$ 150.00$ for the upgrade. Clearly, the average respondent expects the student to be prepared to invest more than $\$ 100$ to upgrade their computer for an E course. That amount would easily cover the cost of a web cam and audio capabilities and the failure of a larger percentage to recommend requiring a web cam suggests that many respondents are unaware of the low cost of these upgrades. This statement was placed after the two statements relating to obtaining a web cam and audio capabilities and, presumably, did not influence responses to those two.

\section{Figure 5}

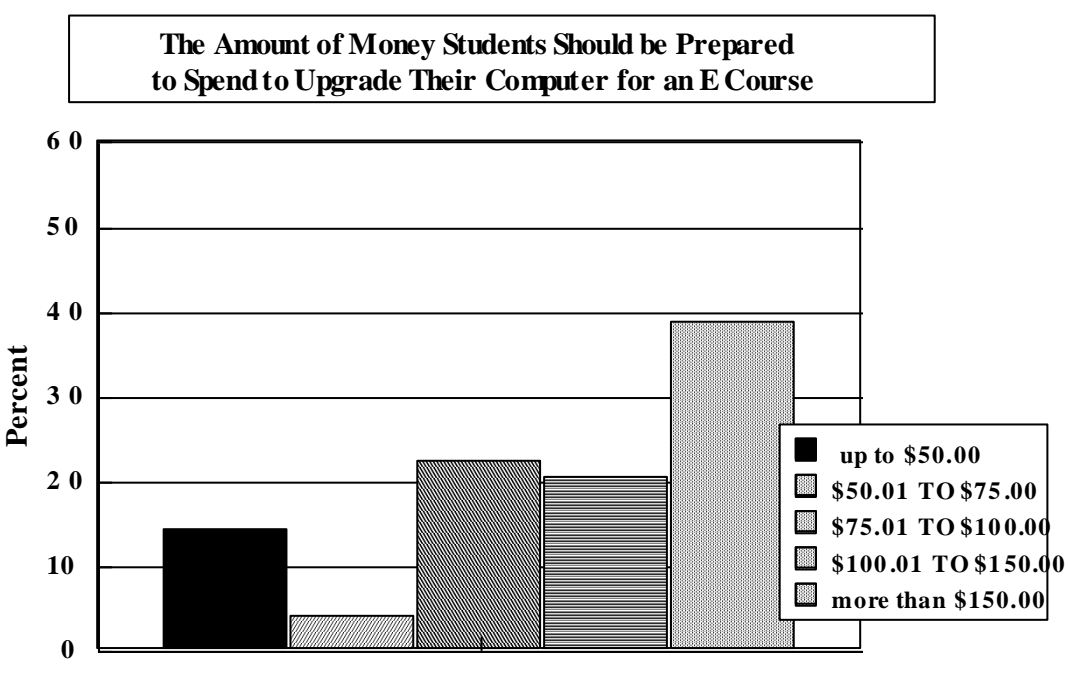

A related issue is the possibility that the student registered for the course is not the student actually completing the on-line examination. Another statement said Afaculty should compare images from a photo ID with the "web cam" image when monitoring examinations completed on-line to insure that the student registered is actually completing the examination. @ As shown in figure 6, almost half (44.9\%) of the respondents agreed with the statement while only $20.4 \%$ disagreed. With about $80 \%$ not objecting to the use of digital photo IDs as a control measure when monitoring on-line 


\section{Number 7}

examinations, the measure appears to be an acceptable method of insuring that the student taking the exam is the same student who registered for the course.

The potential for a Asubstitutee to complete assignments on-line also exists. Another statement which said Afaculty should compare images from a photo ID with the "web cam" image when monitoring homework assignments completed on-line to insure that the student registered is actually completing the assignment. @ As seen in figure 7, only 20.9\% agreed and 50\% disagreed. Perhaps accounting chairs do not believe that homework assignments are important enough factors in the grading process to motivate employing the use of a surrogate to complete the assignment or to use control measures to insure the identity of the person completing the assignments.

Another statement pertaining to the use of a web cam said Afaculty should compare images from a photo ID with the "web cam" image when conducting on-line "chat" rooms to insure that the student registered is actually participating in the "chat" room. @ As seen in figure 8, only $18.4 \%$ of the respondents agreed with the suggestion of comparing images from a photo ID with a web cam image to verify that a student participating in a chat room discussion was the same student registered for the E course. Nearly half (44.9\%) disagreed with the idea and $36.7 \%$ were neutral. As with homework assignments respondents do not endorse the use of a web cam in chat rooms.

\section{Figure 6}

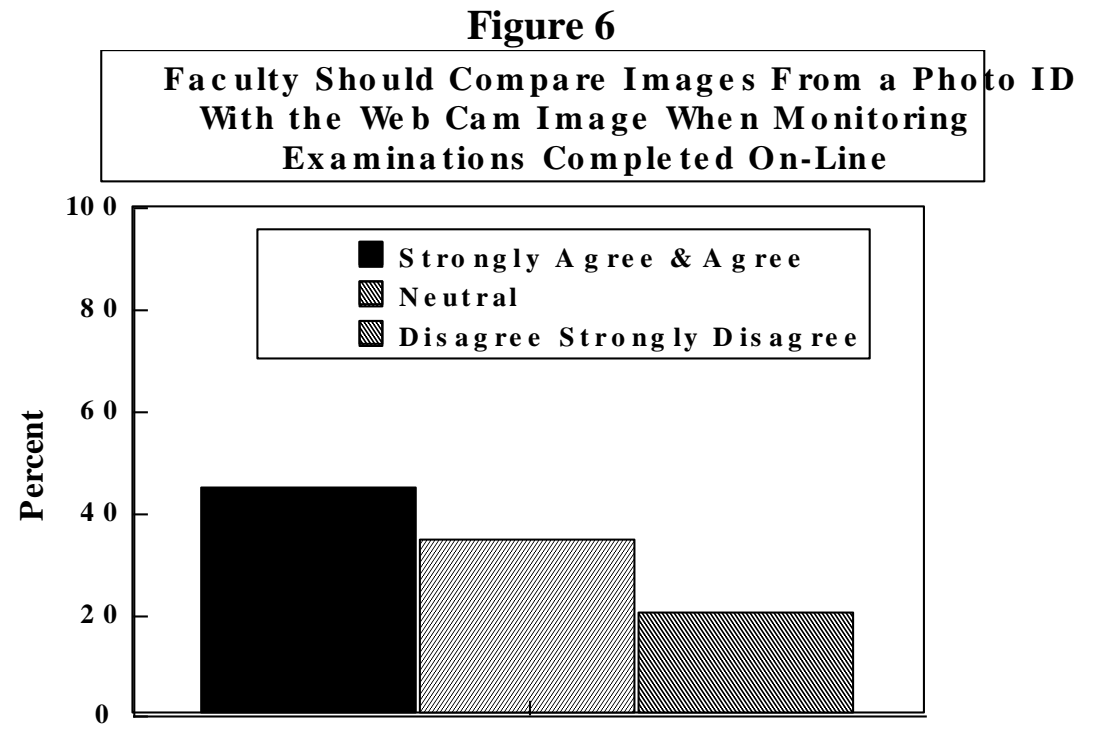

Figure 7 
Faculty Should Compare Images From a Photo ID With the Web Can Image When Monitoring Homework Assignments Completed On-Line

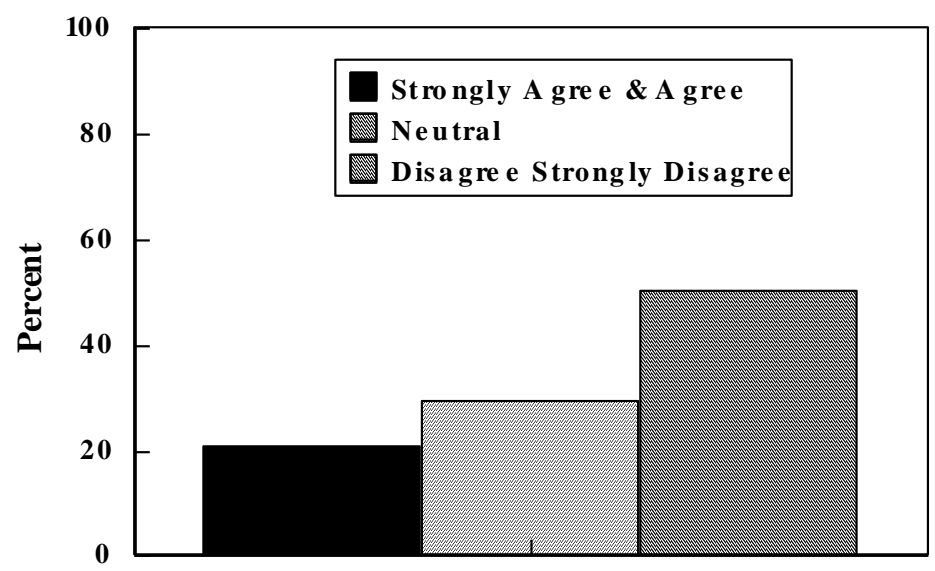

\section{Demographics}

Response data indicates that the typical respondent is chairperson of an accounting department in a public university with a total FTE enrollment of about 5,000 students. The college of business has slightly more than 1,000 FTE students and about 200 of them are majoring in accounting. In more than three-fourths of the schools the college of business is accredited by the AACSB and almost half of the accounting programs are accredited with most being accredited by the AACSB. The typical school offers an MBA and half offer a masters in Accounting.

Figure 8

\begin{tabular}{|c|}
\hline $\begin{array}{c}\text { Faculty Should Compare Images From a Photo ID With the } \\
\text { Web Cam Image When Conducting On-Line Chat Rooms }\end{array}$ \\
\hline
\end{tabular}

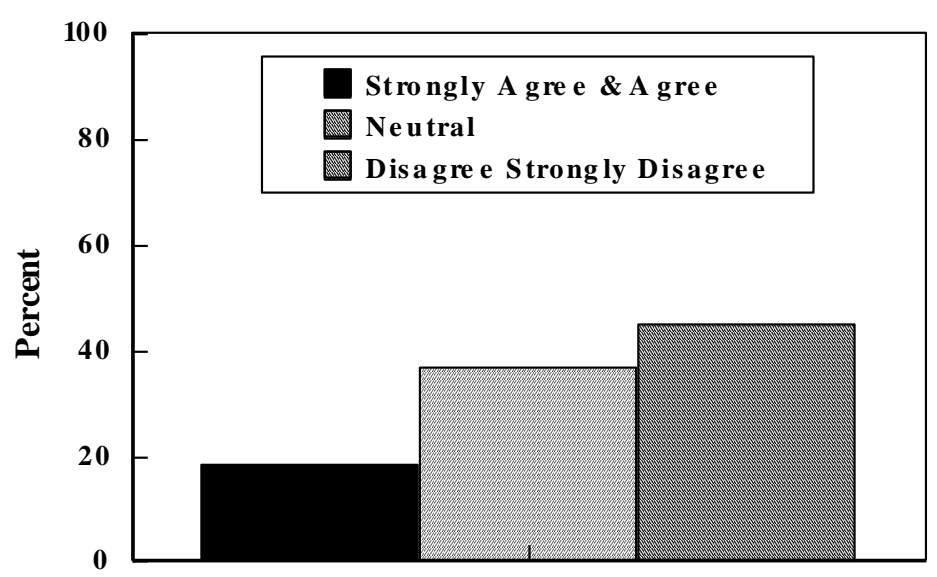

FUTURE TRENDS 
Despite the notable failures (see "Debating the Demise of NYUonline'," 2001) the growth of Internet courses continues unabated. In fact, one university has taken the unusual step of requiring students to complete a distance learning course (Carr, 2000) as part of their traditional campus degree program. Whether the move is intended to strengthen the on-campus degree programs or to shore up a failing distance learning effort is debatable.

Shank (2000) says that "universities want to deliver courses via the web . . b because they are frightened that someone will do it before them and gain more prestige or more student revenue." He adds that "VUs (virtual universities) today seem to be for students that don't have the time to go to real schools. Students get a lot of second rate education consisting of a lot of reading and watching that are interrupted, if they are lucky, by someone's comments on their homework. Sounds like correspondence school, doesn't it? That's what it really is ..."

Oblinger and Kidwell point out that "with distance learning education many of our long-held notions are turned upside down" and Hereford indicates that there is "virtually no consistency in online college courses." Bates observes that "distance learning may be well-suited to some entry level technologies, but more advanced training and hands-on labs still work best in the Classroom ..."

"People who get takeout Chinese food are pretty satisfied with it, because they don't want to go out to a restaurant or cook. But generally, is the quality comparable to a restaurant? No." That quote by Bertagnoli (2001) may pretty well sum up the state of online education at this point in time. While educators, administrators, and other stakeholders may disagree about the current state and future direction of Internet education, its continued growth seems certain. Therefore, continued research is vital if the phenomenon is to develop into an effective complement to traditional on campus courses and programs. The perceived integrity of the process and quality and of the courses must be improved as part of the development.

\section{CONCLUSIONS}

The growth E courses and degrees continues unabated and some sources place the number of institutions offering on-line degree in the 1,100 range and the number of degree programs at about 3,500. E courses represent a major departure from the tradition teaching model because the student and the instructor may be separated by both time and distance. Some technological enhancements are now available that can help bridge the time and distance gulf.

Responses to a questionnaire distributed to chairpersons of accounting departments in the U.S. relating to the use of some of these devices indicated that respondents strongly favored requiring students to provide a digital photo ID and audio capabilities when registering for an E course. However, they rejected the idea of requiring students to provide a web cam that might be used for verifying their identity. Accounting chairs indicated that a student registering for an E course should be prepared to spend more than $\$ 100$ to upgrade their computer.

Respondents also tended to believe, even though they did not endorse requiring one, that students should use a web cam when completing examinations on-line and that faculty should compare the photo ID with the web cam image. However, they do not believe that students should be required to use a web cam when completing homework assignments or that faculty should compare the photo id with the web cam image. Additionally, the use of a web cam and the comparison of a photo ID with a web cam image when students participate in on-line chat rooms were not seen as desirable.

\section{REFERENCES}

1. _ New AFT Report Proposes Standards for Online Programs, Black Issues in Higher Education Vol. 17, Issue 5, February 1, 2001, p. 43.

2. Accredited College Degrees by Correspondence, http://www.collegeathome.com/, 2002.

3. Bertagnoli, Lisa, Education Reservation, Marketing News, Vol. 35, Issue 4, February 12, 2001. 
4. $\quad$ Carr, Sarah, A University Moves to Require Distance Courses, Chronicle of Higher Education, Vol. 47, Issue 8, October 20, 2000, p A48.

5. Deakin, Michelle Bates, The Failings of Distance Learning, Computerworld. Vol. 35, Issue 5, 2001.

6. $\quad$ elearning, http://www.elearningmag.com/, October, 2001.

7. $\quad$ Eisenberg, Daniel, Cheating in the Virtual University, Virtual University Journal, February, 1999.

8. Gaskin, James E. \& Calera, Robert E., Virtual Learning Struggling to Make the Grade, Inter@active Week, Vol 7, Issue 4, August 28, 2000, p 28-9.

9. Hereford, Lady, Virtually No Consistency in Online College Courses, Community College Week, Vol. 12, Issue 15, March 6, 2000, p 8-9.

10. Oblinger, Diana \& Kidwell, Jill, Distance Learning Are We Being Realistic? Educause Review, Vol. 35, Issue 3, May/June 2000, p 30-37.

11. Saunders, Gary, A Comparative Analysis of Distance Learning Delivery Methodologies, presented to the 9th IAAER World Congress of Accounting Educators, Hong Kong, China, November, 2002.

12. Smith, W., The Advantages and Disadvantages of Online Delivery of Accounting Courses: Pitfalls to Avoid, Presented at the Fiftieth International Economics Conference, October, 2000. Charleston, SC.

13. Svetcov, Danielle, The Virtual Classroom vs the Real One, Forbes, Vol. 166, Issue 7, p. 50-52, September 11, 2000.

14. Vasarhelyi, M. A., \& Graham, L., Cybersmart: Education and the Internet, Management Accounting, Aug., 1997, p 32-36. 